\title{
Japanese Cooperation for Urban Planning in the Old Capital of Damascus
}

\author{
Kosuke Matsubara \\ Faculty of Engineering, Information and Systems, Urban Planning Studies, University of Tsukuba, Ibaraki 305-8577, Japan
}

\begin{abstract}
Historic cities are cultural achievements that are gradually created by inhabitants over the centuries. In developed countries, the conservation of historic cities seems to be generally acknowledged as a method of community development that does not depend on huge exploitation. On the other hand, no sufficient countermeasures have been taken in developing countries because most native stakeholders are still interested in development. Here the author could focus on so-called "international cooperation”, but urban conservation for historic cities where inhabitants actually live is still a minor consideration except for some government-based conservation projects for monuments and isolated examples of cultural heritage. In this paper, the example was taken of a conservation project which has been carried out by JICA (Japanese International Cooperation Agency) in Damascus, the old capital of Syria. The target area for the project is “Qanawat South”. Although the origin of “Qanawat South” dates back to the Roman age, efforts for urban conservation have not been well organized, partly because the area is located outside of the so-called old city registered as a world heritage site. For example, the master plan of 1968 indicated the redistribution of the traditional quarters, while some conservation laws have been restricting the regeneration of the area. Moreover, there is not yet any consensus among the stakeholders concerning the historical value of the quarter, they are still questioning why the area should be conserved rather than being freely sold or developed and what and how they should contribute to conservation. Based on analysis of the actual situation of Qasr al-Hajjaj Street, this paper examines a method called "restoration-type” facade improvement adopted by JICA, for which the final goal is not only to maintain the appearance of the street but also to activate the life of the habitants of the street.
\end{abstract}

Key words: JICA, Gyoji Banshoya, Damascus, facade improvement, architectural vocabulary.

\section{Introduction}

Since the Japanese planner Gyoji Banshoya (1930-1998) elaborated in cooperation with Michel Ecochard the master plan of Damascus in 1968 (still active today) [1, 2], Japanese/international cooperation in Damascus has been ongoing as one of the rare cases in which Japanese architects and planners are working in the Middle East [3, 4]. The reported example here is the latest technical project named "Damascus metropolitan area urban planning and development project” which started in September 2009 and will be completed in August 2012 [5]. One of the principal objects of the project is to suggest conservation ideas for the local heritage area, “Qanawat South” (surface: $0.28 \mathrm{~km}^{2}$, population:

\footnotetext{
Corresponding author: Kosuke Matsubara, Ph.D., research field: urban planning history. E-mail: matsub@sk.tsukuba.ac.jp.
}

8,870), and in particular, those involved are suggesting a facade improvement project for a historic street called Qasr al-Hajjaj [6].

The problems with the degradation of the living environment along the Qasr al-Hajjaj Street are partly caused by the decrepitude of traditional houses made of woods and bricks. Although previous surveys did not aim for structural reparation, it was certainly recognized that one of the reasons for the degradation of the living environment is the fact that habitants easily abandon their houses and demand rapid re-development regardless of historical value. This is a vicious cycle that has continued for some decades but specialists participating in international cooperation projects can not always interfere with this since the project terms are limited. What such specialists can do is to give the habitants an occasion or the awareness to be motivated to resolve the problems by themselves. 
Facade improvement is not a complete resolution of the problems but can be a first occasion to get habitants participating in the efforts. Specifically, it is expected that habitants start taking pride in their town and participate in the management of the living environment taking advantage of the apparent facade improvement. In this case, specialists make proposals and contribute to this process within a limited term.

The object of this survey is to examine "restoration-type" facade improvement based on the analysis of the actual situation of Qasr al-Hajjaj Street. Some similar projects have been previously carried out in Syrian cities where many historic landscapes such as old city souk and historical road outside of city walls still exist. The difference between these previous projects and JICA (Japanese International Cooperation Agency) projects is that they adopted drastic improvement methods such as the uniform replacement of zinc shutters and the standardization of the height of buildings, while JICA tries to re-discover and maintain the original state of the facade as far as possible, defining facade improvement as "restoration-type" facade improvement.

The methods taken in this survey are as follows: (1) chronological survey of the reasons why restoration-type facade improvement is necessary (Section 2); (2) preliminary field survey to examine the method to analyse the facade (Section 3); (3) elaboration and analysis of an integrated facade plan based on field surveys of facades in relation to spatial composition in plans and the extraction of the elements composing the facade (Section 4); (4) clarification of obstructive elements in the original historic facade and analysis of their background and actual situation (Section 5); (5) final examination of the trial proposed plan (Section 6); and (6) suggestions to restore original facades based on the findings of this survey (Section 6).

\section{Spatial Characteristics of the Street and the Necessity of Facade Improvement}

\author{
2.1 History of the Urban Formation and Spatial \\ Composition of the Street
}

The target area of "Qanawat South" is located in the south west of the old walled city of Damascus called "Old Damas". The fact that it is located outside the old city means that the area is not within the scope of the world heritage site which was registered in 1979. However, the area is still an important historic area which dates back to the Roman age and which was developed in the 16th century when the Ottoman Empire started to rule Syria [7].

There are two historical roads from the Bab Srij which is the south west gate of the old city. Bab Srij Street was developed as a souk (traditional shopping street) connecting Damascus with the ports of the East Mediterranean, while Qasr al-Hajjaj Street, which was a transport road connecting to southern villages or even a pilgrimage to Mecca, was developed as a housing area for new residents such as Turkish bureaucrats [8]. Nowadays, the street is still a densely populated area with traditional houses with courtyards.

Although the street seems simply to be a crowded area, there is a kind of spatial order. Qasr al-Hajjaj Street is a north-south axis which is almost a straight line from the Bab Srij Gate to the south border of the area. On the other hand, there are small alleys that cross the north-south axis from east to west-18 alleys in total, seven of which are on the east side of the axis and 11 on the west. There are two blind alleys in the east (28.6\% of all east alleys) and eight in the west $(72.7 \%$ of all west alleys), showing the difference between east and west. In the south of the area where modern apartments are rarely built, traditional spatial composition of housing as a "private space" accessed with blind alleys can still be found. 


\subsection{Urban District Planning System and Changes in} Street Landscape

Changes in streets caused by modernization include the re-construction of traditional two storey or three storey houses into modern apartments (four floors maximum) implemented by the district plan. The actual district plan was elaborated by the Damascus governorate from the 1970s onwards based on the principles of the master plan of 1968. In the master plan, Ecochard and Banshoya predicted the decrepitude of traditional houses made of dry brick and suggested the renewal of some historic housing areas including the target area.

The district plan shows a clear road line to be respected for the new construction, followed by a strict rule of a $2 \mathrm{~m}$ set-back from the original lot line. As a result, the street is now regarded as an “existing-misfit” (anomaly). In fact, this district plan is a system to allow the construction of modern apartments, which is more rational from the viewpoint of land use and adjusting the road line. With this system, the streets are widened and a modern block is created, almost automatically creating a modern built-up area. It is clear that the district system is based on modernist policies originating from CIAM (International Congresses of Modern Architecture).

\subsection{Actual Living Environment and the Necessity of Facade Improvement}

There are no ideas for conservation in the district plan adopted by the Damascus Governorate but the Department of Antiquities of the MOC (Ministry of Culture) has introduced some systems for historic conservation: 11 "historic monuments" weredesignated in 1964 and a historic protection area was designated for most of the buildings along the street. These conservation systems are quite strict and are given precedent over the district plan. As a result, re-construction in the protected area has become almost impossible even though the houses are severely damaged and should be renewed at least from the viewpoint of the master plan. In addition, achieving the mutual agreement of the habitants is difficult in general so the implementation of the district plan is now coming to a halt. In such a situation, the decrepitude of traditional houses has become more and more serious and various problems such as room deformity, wall and roof collapse and the unsanitary state of the dried brick walls have occurred. On the whole, habitants can not re-construct houses in the protected area but some modern apartments with incoherent set-backs can be found outside of the protected area.

Basic actual land use is for housing but some houses have small shops in the front (Fig. 1). The street, which is $514 \mathrm{~m}$ in length and between $4 \mathrm{~m}$ and $6 \mathrm{~m}$ in width, is a one-way street but traffic is heavy and it is not safe for pedestrians.

In fact, the situation on Qasr al-Hajjaj Street is quite different from that of Souk Midkhat Pacha which was the object of a facade improvement project in the past (Fig. 2) [9]. Past projects included some radical methods such as replacing shutters with neo-traditional wooden doors or apparent unification of building heights and wall finish. However, these radical methods are still debatable since one of reasons that the old city is attractive stems from its spatial variety.

Even it is though connected with Souk Midkhat Pacha, Qasr al-Hajjaj Street is a modest curve and basically a housing area. It is not possible to neglect the small differences in houses and shops, the differences in building materials and the differences in height because these small differences are the characteristics of each building. The unification method is not appropriate for Qasr al-Hajjaj. It is necessary to search for a new method of authentic restoration of the original historic facades based on minor repairs conducted in the traditional manner but that also helps the habitants to improve their living environments. 


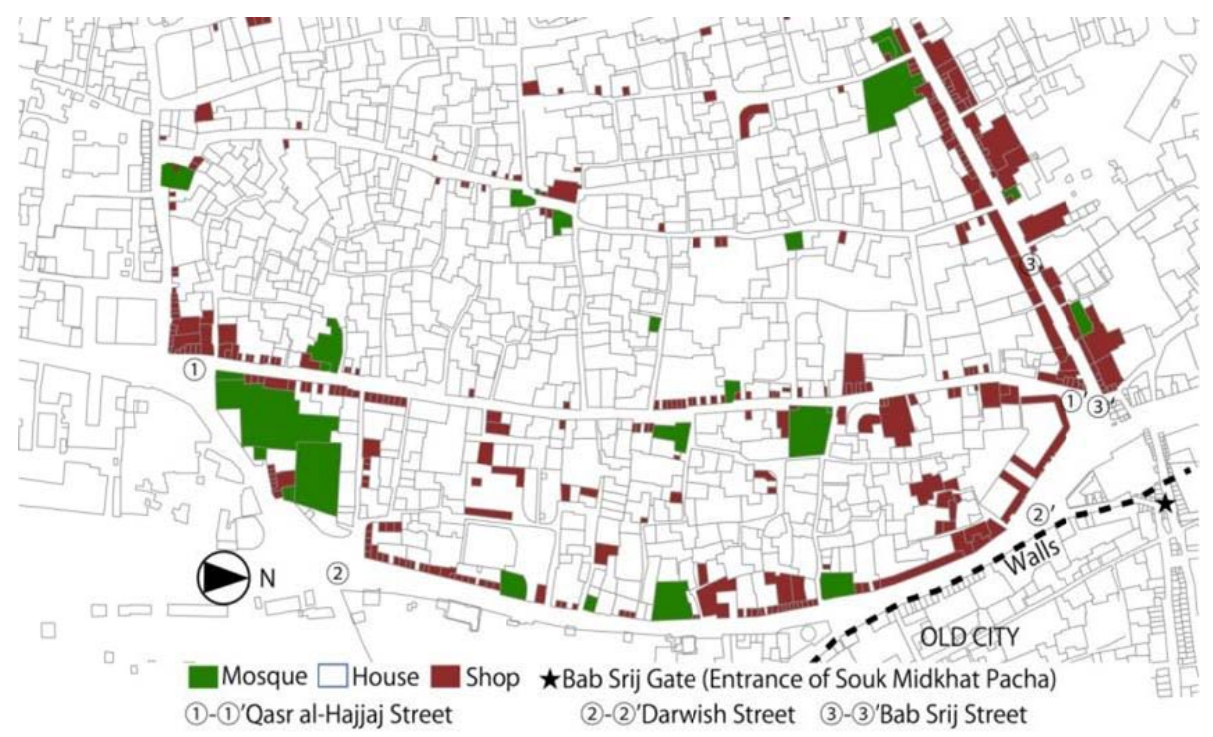

Fig. 1 Actual land use along the street.
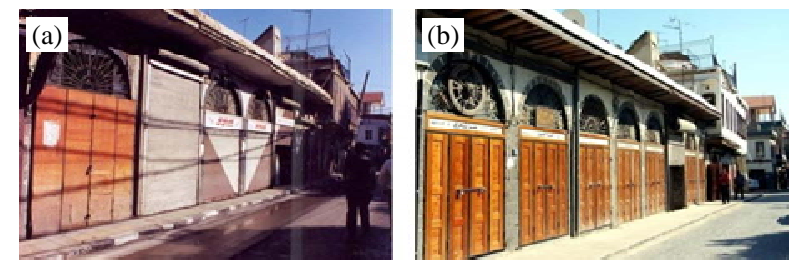

Fig. 2 Case of Souk Midkhat Pacha: (a) before improvement; (b) after improvement.

\section{Current Status and Preliminary Survey}

\subsection{Current Status of the Facade}

Fig. 3 shows an example of a collapsing facade in Qasr al-Hajjaj Street. The author needs to distinguish whether the materials that it is composed of are original or new.

Then the author faces the questions of what the traditional design of Hus was or what the original structure of the roof was. From the viewpoint of revitalizing the street, it is also important to know what kind of shop it was.

So, at the beginning of the project, the author carried out a series of field surveys in order to get an overview of issues in the streets in question.

For example, Figs. 4a and 4b show two balconies. The bases of the balconies are considered to have originally been made of wood but these days some are made of concrete as shown in Fig. 4b. In such cases, should this be replaced with a wooden base? Fig. 4c shows the entrance to Qasr al-Hajjaj. Why wasthe wall built like this? It was probably so that it followed the original height of the buildings, at least for walls. In this case, what should people do to improve the facade?

Figs. 4d and 4e give the impression that there used to be a room here but that it was demolished when a modern apartment was built alongside. In this case, should people restore or reproduce the room to its original state? Fig. 4f shows that naked beams were visible in the facade. This is a typical townscape element. People should accurately distinguish whether they were originally uncovered or covered as shown in Fig. 4g. In addition, Fig. 4h shows a traditional kind of bay window called a Hus. However, it seems made of iron. This is the same in Fig. 4i. Should people accept Hus that is made of iron?

It seems that there are many issues to be discussed concerning historical authenticity, design, materials, structure and some legal matters. The preliminary survey demonstrated that accurate information is required in order to consider issues and their solutions. In particular, the author required plans of the facade with satisfactory details. So the next step was to prepare these plans. 


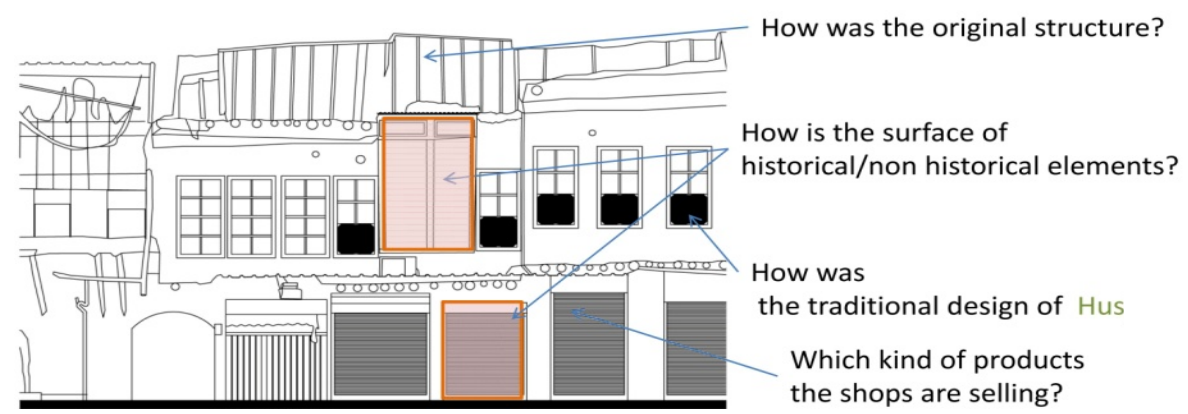

Fig. 3 Collapsing facade in Qasr al-Hajjaji Street.

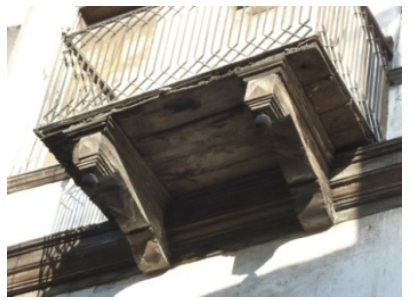

(a) Balcony A

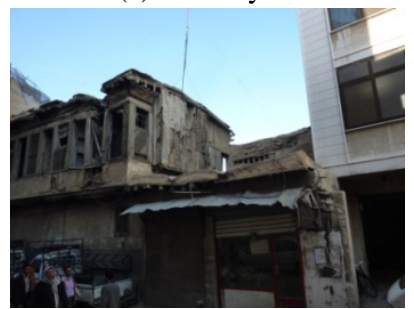

(d) Demolished room

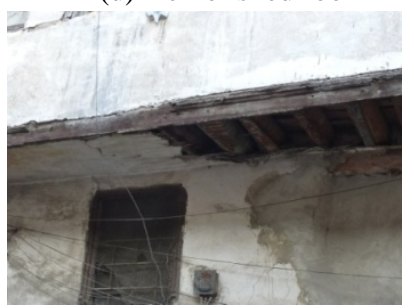

(g) Uncovered beam

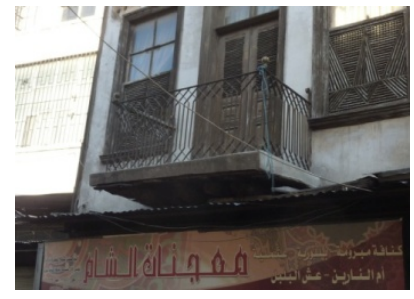

(b) Balcony B

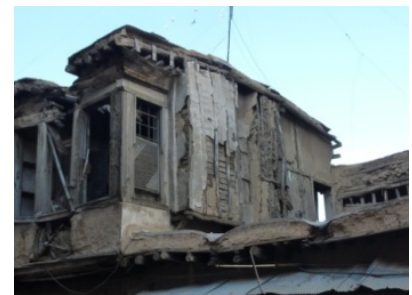

(e) Demolished room

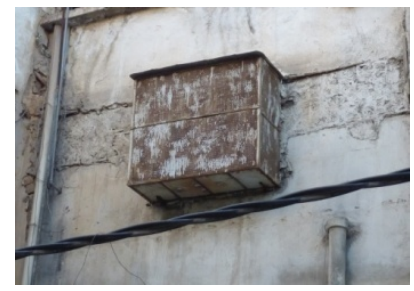

(h) Hus of iron

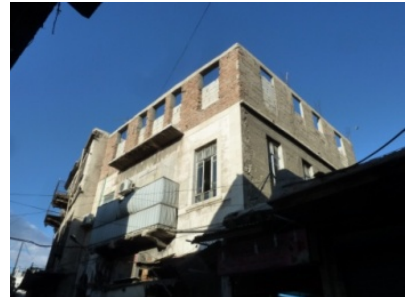

(c) Isolated wall

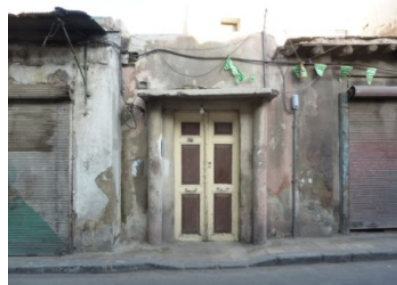

(f) Naked beam

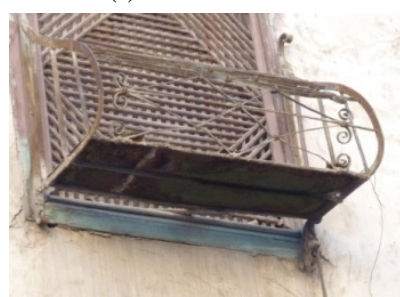

(i) Hus of iron

Fig. 4 An overview of the Qasr al-HajjajiStreet.

\subsection{Creating the Facade Plan}

In January 2011, the first set of plans was created by a JICA team in cooperation with Dr. Sacka's local architectural office. They comprised three plans: (1) facade photos; (2) plan of the actual situation; and (3) proposal plan. Fig. 5 shows an example of the plans for the east side of Qasr al-Hajjaj Street.

In order to roughly estimate the quality of the plans, the author needs to examine the integrity of the facade photos, the accuracy of the plan of the actual situation, and the validity of the proposal plan.
The integrity of the facade photos seems good enough on a technical level but some issues can be pointed out such as the fact that the photos were taken early in the morning in order to avoid people and cars in the images. However, some cars are presented in the photos even though efforts were made to avoid this. Also, because it was early morning, almost all the shops have their shutters closed so it is difficult to judge what kind of shops they are. It was necessary to visit the street and confirm the situation in order to resolve these issues. 


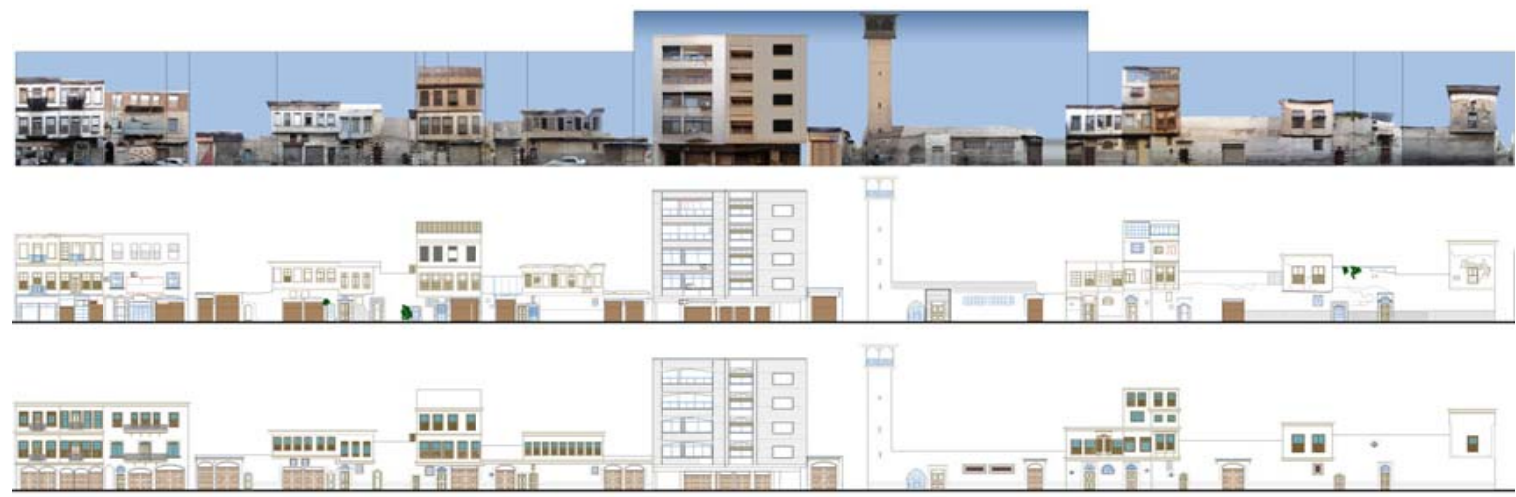

Fig. 5 A part of the first set of plans created in the JICA project (in collaboration with Dr. Sacka).

The accuracy of the plan of the actual situation is quite important because it may be used not only as a base on which to elaborate the proposal plan but also as a database of knowledge and understanding of the characteristics of the facade that will be shared by all those involved and to which the author can repeatedly refer during the project as a whole. From this point of view, this Auto Cad plan seems to describe each traditional facade element well and in detail, for example, Shurfa, Hus or other structural elements such as wooden beams under bay windows and roofs. It also identifies materials. The plans are layered corresponding to standard elements such as a wooden materials layer, an iron materials layer, a shutter layer and a green layer, etc.. In addition, some of these traditional elements have deteriorated so the plan also describes some damaged parts of Klusa, twisted beams, and abandoned Hus. This information suggests serious issues the actual situations are as following: some houses need not only superficial repairs but also structural restoration. The plan also accurately shows the other facade issue which is the disorderly installment of modern equipment such as air conditioners, electricity cables and shutters.

The provisional proposal plan contains various and important suggestions for facade improvement. Based on the principle of preserving traditional architectural features such as arches and balconies, the proposal plan indicates many tasks such as the restoration of old houses to their original states, the repairing of damaged walls and roofs, the installation of wooden doors as an alternative to shutters and the introduction of traditional-style decoration to modern apartments, etc.. It is important to evaluate this kind of proposal plan by examining its validity. This will be examined later.

\subsection{Cluster Analysis of Facade Plan}

The facade, as far as concerning to its appearance, is composed of various townscape elements. The townscape elements can be defined widely and observed in many levels according to their properties or characters. In fact, there is not exclusive method to analyze a facade and its townscape elements. However, as reported in our previous research [6], the method called "architectural vocabulary" seems broadly adopted as an useful method, especially for the case of the historic city.

The point about the "architectural vocabulary" is an analogical approach inspired by the linguistics. According to the linguistics, the language is logically clustered as a structure of ideas about the creation. Based on this hypothesis, the architectural vocabulary is a method to organize and describe the composition of building or urban fabric. The most famous case of this kind of approach may be the "Pattern Language" supposed by Alexander in 1970s [10]. And inspired by Alexander, Tunisian-American planner Hakim 
examined his own theory for the case of the old city of Tunis and published "Arabic-Islamic Cities” in 1986 [11]. These examples can be called in general "architectural vocabulary" which is a simple method to cluster the object and understand them naturally but logically as well.

One of the advantages of this creative, imaginative and even poetic approach is that architectural vocabulary is useful as a communication tool among the habitants, the administrators and the project member because it is based on language. So it is a suitable approach also from the viewpoint of the promotion of public awareness to improve the townscape in the area, the first purpose of this project. In searching old words around traditional housing, construction and lifestyle which are being disappearing even among Syrian habitants, the facade of the target area is expected to be analyzed and improved by habitants own selves.

\subsubsection{Quarter Level}

For the first clustering of the facade, the street is divided into quarters according to lane partitions. By doing this, important information can be obtained in order to discuss the relationship between the facade and its surrounding buildings or urban fabrics in general. For example, one quarter may seem more crowded than another but the former contains only buildings behind the facade while the latter contains large courtyards with plenty of greenery. Considering the height of buildings and usage behind the facade, there is perhaps a trend in which high (3 or 4 storeys) buildings do not have enough open space while low (1 or 2 storeys) buildings have a relatively high proportion of open space. It seems that this tendency also can be observed in other quarters, especially to the south where the greenery spills out the courtyards and is visible in the facade. On the other hand, modern apartments do not have any open spaces. The existence of the courtyard, which is quite an important factor in preserving private space, may have a close connection to the height of buildings in the facade.

\subsubsection{Building Level}

Fig. 6 shows further clustering analysis of the facade for quarter level, building level, and element level and that townscape elements in each level compose the whole facade. Fig. 6 is an example of a quarter.

In this quarter, there are some traditional houses and a five storey modern apartment. On the building level, it is possible to make two clusters: one of traditional buildings and one of modern buildings. For the traditional buildings cluster, it is not easy to count the exact number of traditional houses because they are joined by common walls. However, it is clear that these buildings have some doors to houses and shutters of small shops on the ground floor. As mentioned above, this area was built as a housing area when the Ottoman Empire occupied Damascus in the 16th century. This example suggests that this was originally a housing area then some houses were converted into shops over time. The shops are small and it may be that there are no shops on the first floor or above. These floors seem to have remained as houses at least by appearance, but some of them may be abandoned or used as storage for the shops.

On the other hand, the apartment building is a typical modern architectural structure constructed in the 1970s or 1980s according to district plans influenced by Ecochard-Banshoya. The building line is set back according to the rules in order to widen the street to accommodate cars. In the frontage of the ground floor, there is a sidewalk designed as a corridor with columns. This corridor contains some shop shutters. The district plan was intending to destroy all the historic facade of Qasr al-Hajjaj Street to create a wide street with a shopping corridor with columns. Needless to say, this plan is out of date and fortunately the area has been registered as a protected historical area. However, this apartment building is also an ineluctable element of the facade since it can not be easily demolished. On the whole, the facade of this quarter has at least two different types of facade on the building level. 


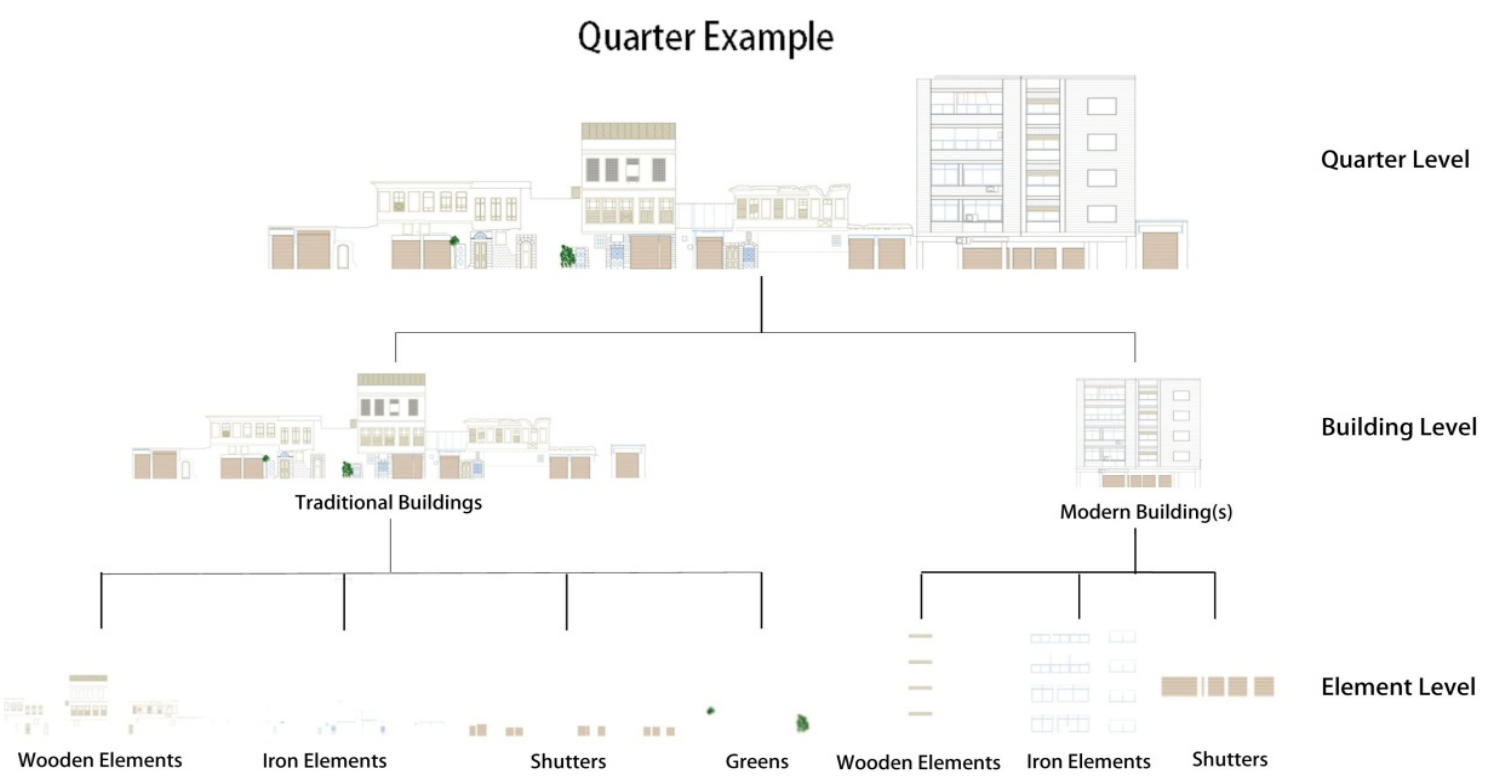

Fig. 6 Example of clustering analysis of facades at quarter level, building level and element level.

\subsubsection{Element Level}

For the element level, take the example of the traditional buildings in Fig. 6. The plan is made up of several layers and some of these indicate facade elements. In fact, the definition of elements is still vague, sometimes it means materials such as wood or iron in general and other times it means specific parts such as shutters or greenery.

Wooden elements are mainly groups of window frames and covers including Hus. These are particularly concentrated on the first floor and above. Windows are basically rectangular and size and design are uniform. This may be one of the reasons why the whole facade seems quite well arranged and regulated in a traditional manner. However, each window may have slightly different and original characteristics in their composition or design. In contrast, uniformity is less obvious on the ground floor. It appears that windows tend to be relatively small, square in shape and located higher than the doors. This tendency can be explained by the traditional discipline of Islamic urbanism in which is standard not to permit people to look in from the street. According to this same traditional discipline, house entrances should not be located on the main street but on narrow lanes. In the case of Fig. 6, there are some doors on the facade showing that the discipline is not clearly adopted here. It is necessary to check all the houses on the corner in order to examine this in more detail.

It sees that iron materials are used mainly for the doors of some of the houses. It is also used for transom frames on the top of doors and small windows on the ground floor. Other iron materials are not so popular and limited to scrap materials such as small eaves for shutters or Hus supports.

Shutters refer to shop shutters made of galvanized iron. When the shops are open, the shutters are rolled inside a box at the top of the shop entrance which doubles as the shop signboard. Today, however, they are considered as a negative factor in the townscape and are subject to replacement with new wooden doors. In this sample area, there are not so many shutters and each shops sells a variety of articles. In other words, this is not a traditional souk specializing in specific products like the souks in the old city or in Bab Srij Street.

For the greenery element, there seems to be only two trees in fixed pods on the sidewalk. It is uncertain whether the pods were installed by inhabitants or the administration. Either way, trees are quite an 
important element of the townscape, so people need to consider how to maintain these.

For further information, it would also be meaningful to make an analysis of the design of each separate element. As mentioned above, each window or door is slightly different. It is necessary to gather all the elements and make a database in order to analyze this. For example, Figs. 7 and 8 list the

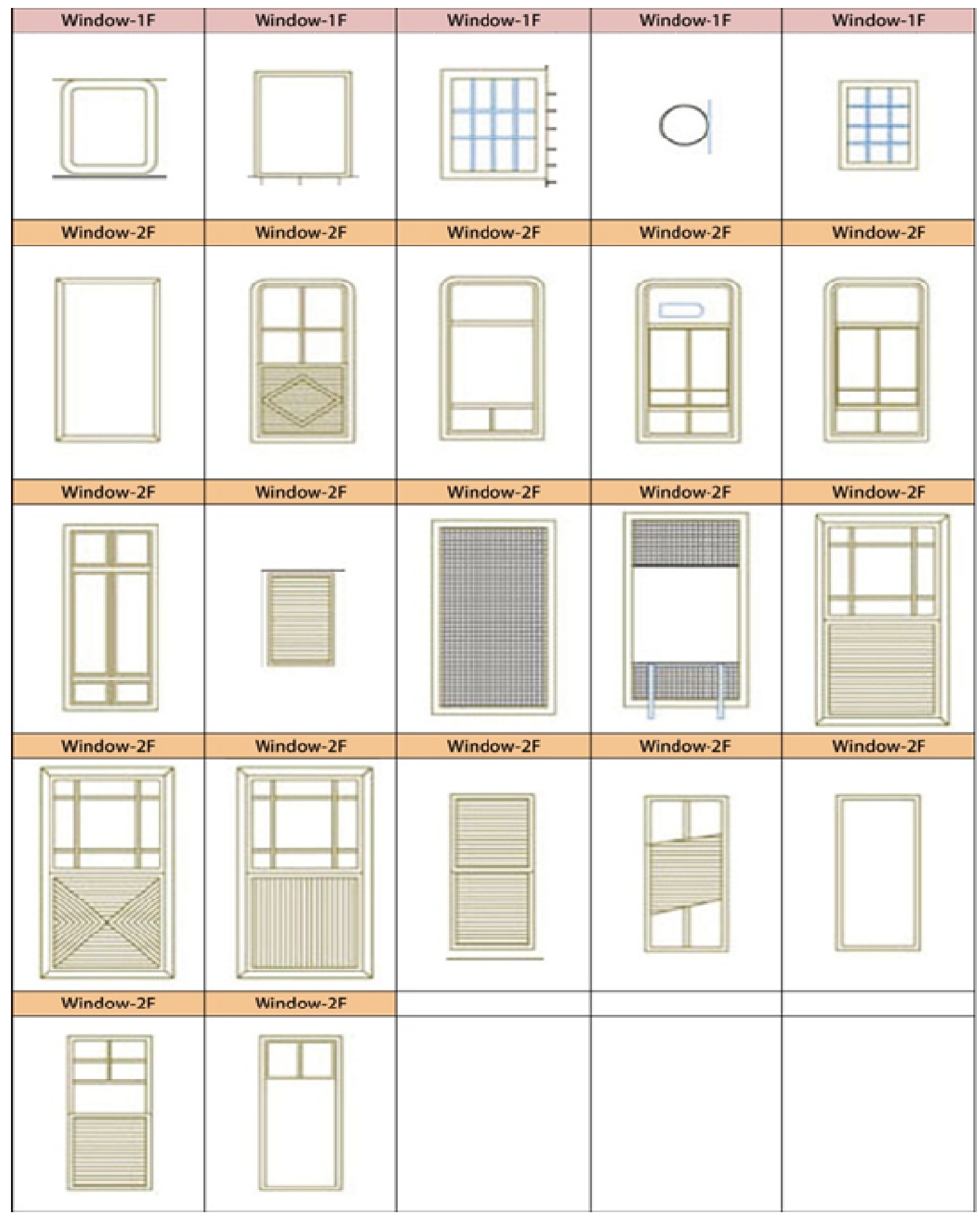

Fig. 7 List of elements (window covers). 


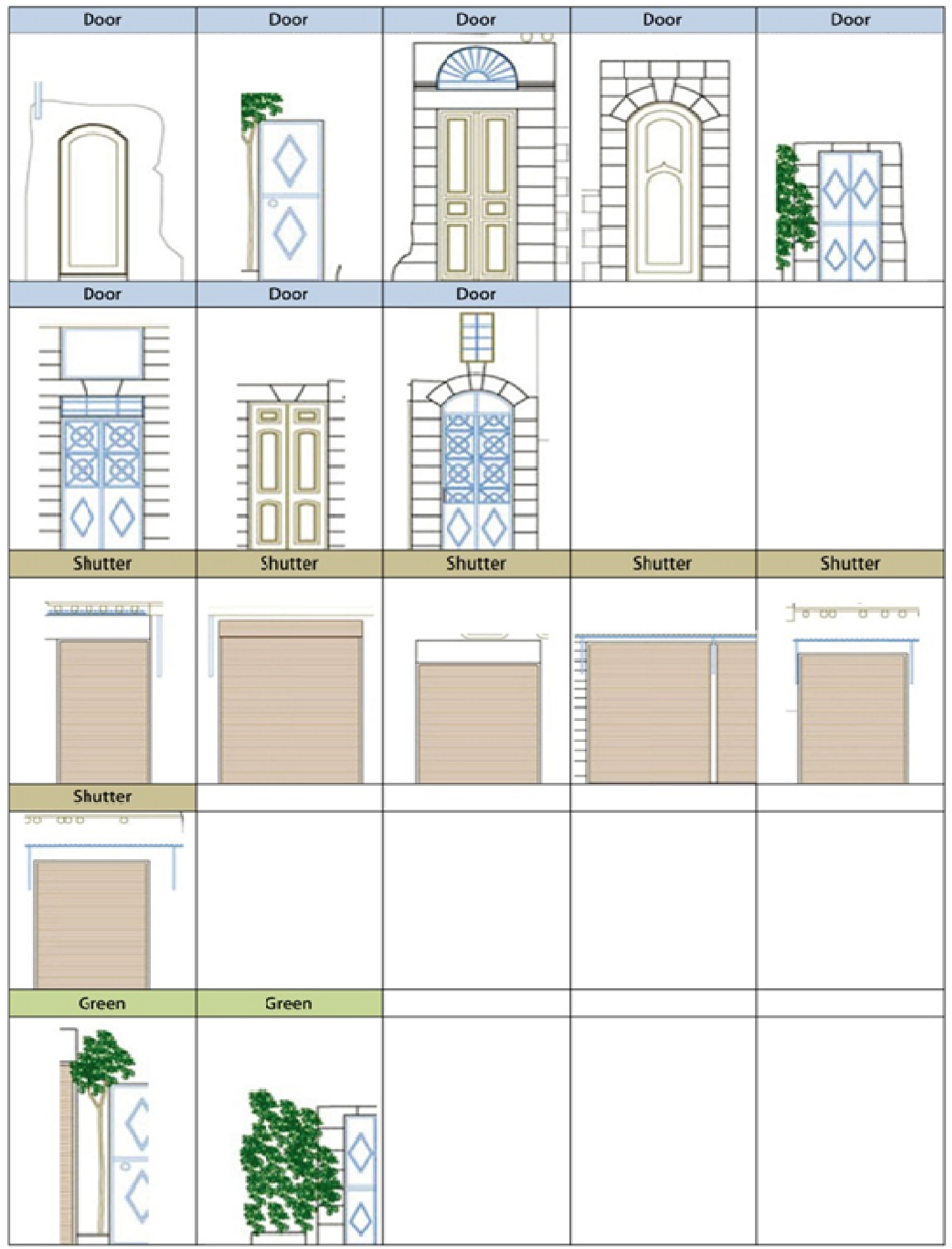

Fig. 8 List of elements (doors, shutters and greenery).

elements found in the traditional buildings. It is possible to distinguish each window or door based on the CAD (computer-aided design) data for the facade plan. For example, the authors can consider the age of 
materials, differences in shapes and frame composition, etc.. The significance of the elements will become clearer after a historical survey or interviews with inhabitants. The database will probably be useful for creating a design menu to which artisans can refer when working in each building.

On the whole, many facade elements are found in the different levels. Some of them seem to be related to the traditional discipline of Islamic urbanism. It is important to understand the facade as a whole consisting of various levels and elements.

\section{The Facade of Qasr al-Hajjaj Street}

\subsection{Overview of the Facade}

In the project, people made various plans and maps of Qasr al-Hajjaj Street. Here, the author has unified a floor plan and a facade plan for research purposes. The facade plan, which was created from the facade photos, describes all the elements of the facade.

Before the author examines these elements, let people look at an overview of the street. Existing houses of two or three floors are sharing walls and are joined with each other. The borders of these houses are plastered with Kulsa in the traditional way it is not possible to distinguish between them on the facade plan. However, there are blocks separated by alleys: eight blocks on the east side and 12 blocks on the west side of the street. Facade analysis will be conducted for each block as a separate unit for examination.

Modern apartments, which are the highest buildings except for the minarets of mosques, number 2 on the east side and 3 on the west. For example, apartment A is set back from the street and moreover its ground floor houses shops with a pillared corridor whose design originally dates back to the French mandate period. From the viewpoint of conservation, it can be said that this modern apartment building detracts from the traditional facade. Because of the existence of these modern apartments, traditional-type facade improvement is not possible.

\subsection{Basic Elements of the Facade}

Four categories of essential elements to be analysed have been pinpointed on the facade plan as follows (Fig. 9): (1) doors; (2) windows; (3) shop shutters; and (4) decoration (including traditional balconies called Shurfa, revealed beams etc.). Small and optional elements such as individual tiles, materials for finishing walls that are not part of the structure, modern equipment such as electric cables or exterior parts of air conditioners and greenery are excluded from the analysis. The elements of the four categories are subdivided into wood/iron and 1st/2nd/3rd floor, etc., in order to understand the number, surface and percentage of the elements as essential information for facade evaluation (Tables 1 and 2).

\subsection{Analysis of the Elements}

Based on the essential information organized in Tables 1 and 2, it was examined whether they are original or traditional elements of the facade or not. The viewpoints the author takes into account are the original state of the facade as an ideal goal of facade

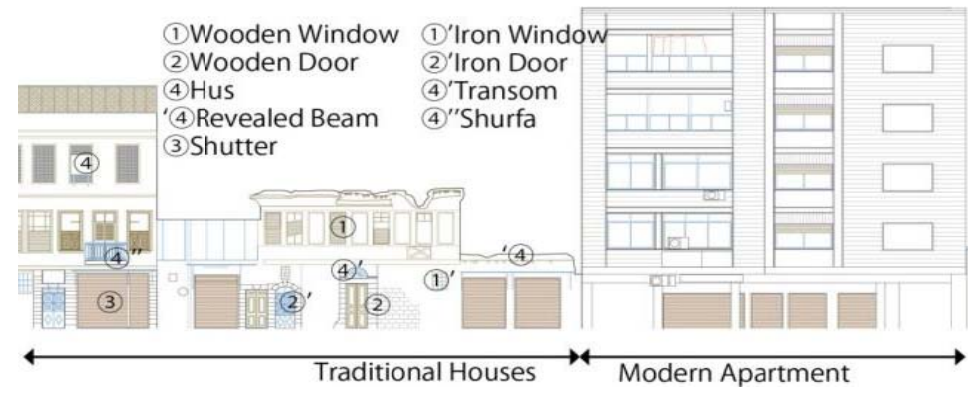

Fig. 9 Examples of facade elements. 


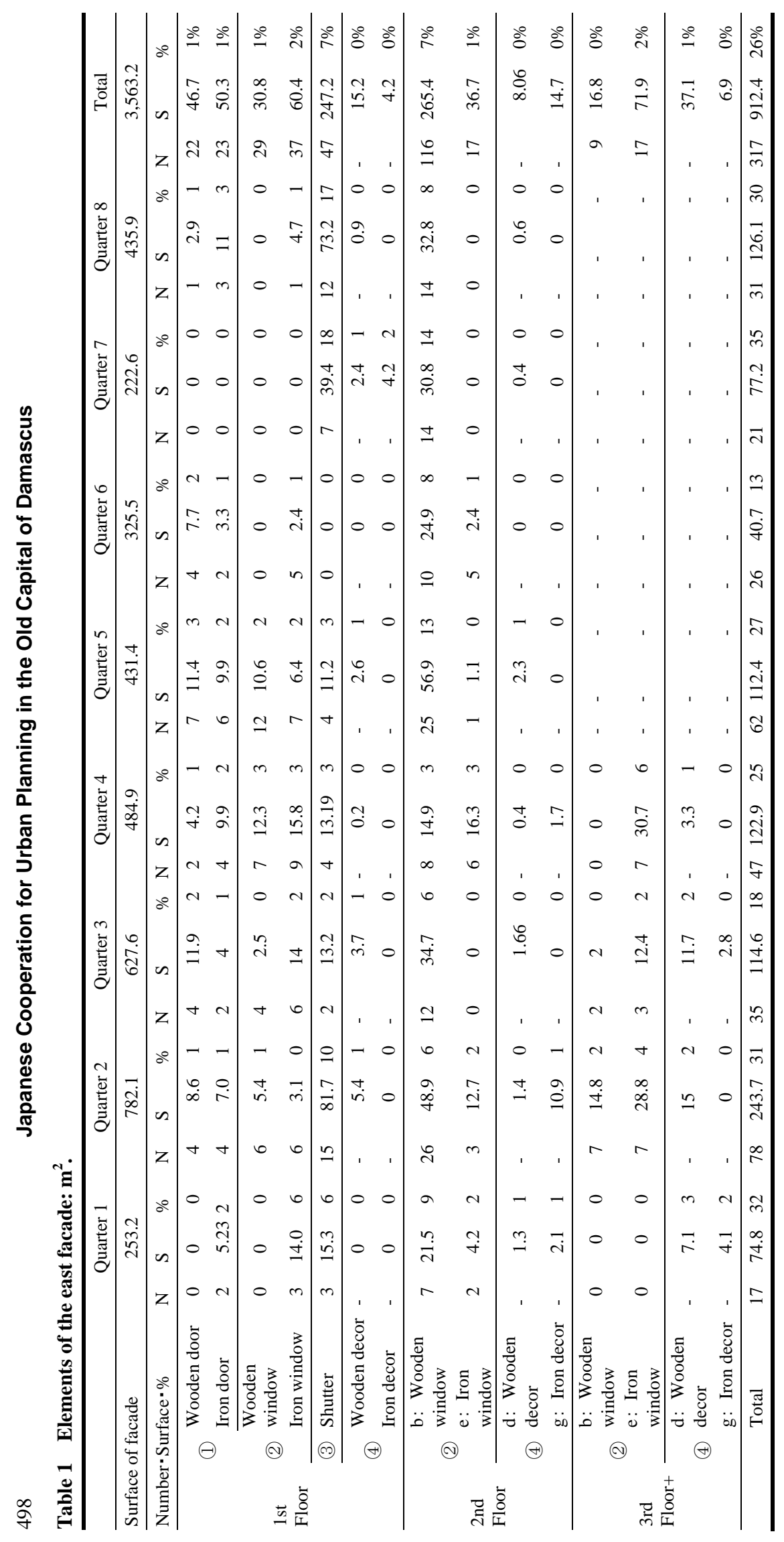


improvement and the traditional spatial composition of commercial and housing areas in relation to the floor plan. Illustrating some examples of elements in Figs. 10 and 11, and the overview of the facade plan in Figs. 12 and 13, the elements are analyzed as follows.

\subsubsection{Doors}

The doors are openings on the first floor. There are 40 on the east side and 49 on the west side of the street. The average span of these doors is $10-13 \mathrm{~m}$ but spans are not the same and are related to the composition of houses that have courtyards. In general, because of Islamic customs respecting privacy, the doors of a house located at the intersection of a street and a small alley tend to face on to the small alley as a private space and are not to be opened onto the street which is more a public space. Examining all the doors of the houses located at intersections today, most doors face on to the street regardless of Islamic custom, but a tendency to face doors on to alleys was observed in some cases in the south part of the street where traditional spatial composition still remains. Doors were originally made of wood but they are being replaced with new materials such as iron and over half of doors today are made from iron. Almost all doors are arched and 16.5\% have arched transoms. Although there are only a few compared to the case of the old city, the arch is rarely a traditional element. On the whole, doors, which are positioned corresponding to the spatial composition of the street and traditionally decorated, are considered as an important original element to be restored.

\subsubsection{Windows}

Windows are located on each floor but appearance between the 1st floor and other floors is different. Windows on the 1st floor (66 on the east side and 91 on the west) are relatively small and not unified in specific form. On the other hand, average height from the ground to the bottom of the window frame is about $200 \mathrm{~cm}$ which is quite high. This is due not only to the common custom in Damascus of raising the floor to avoid the cold, but also to the Islamic custom of privacy so that passersby can not look in through the window.

The windows on the second floor are many and huge, their total surface is the second largest element of the whole facade. There is unity of size and form and window frames are traditionally decorated. Movable wooden window covers Hus, which means "wooden sculpture", covers the windows. There are also bay windows which give the impression of three-dimensionality to the street landscape. Not so much difference is found between the windows of the 2nd floors and those of the 3rd floors. From the viewpoint of window frame materials, the numbers of

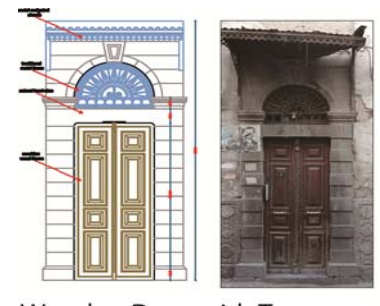

Wooden Door with Transom

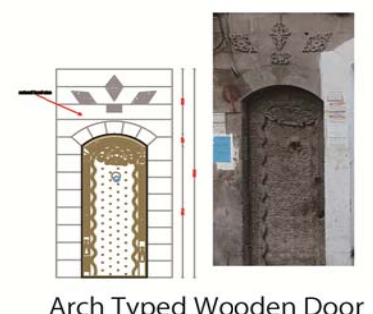

Arch Typed Wooden Door
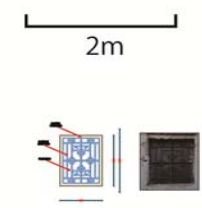

Iron Window 1st Floor

Fig. 10 Examples of elements on the 1st floor.

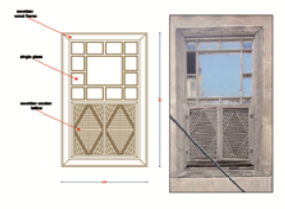

Wooden Window 2nd Floor

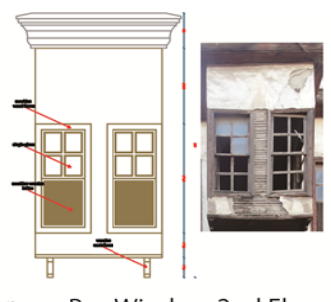

Bay Window 2nd Floor

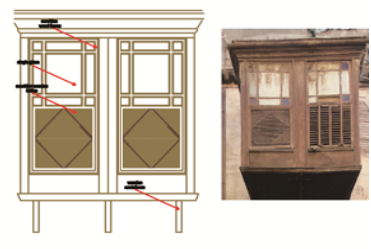

Hus 2nd Floor

Fig. 11 Examples of elements on the 2nd floor. 

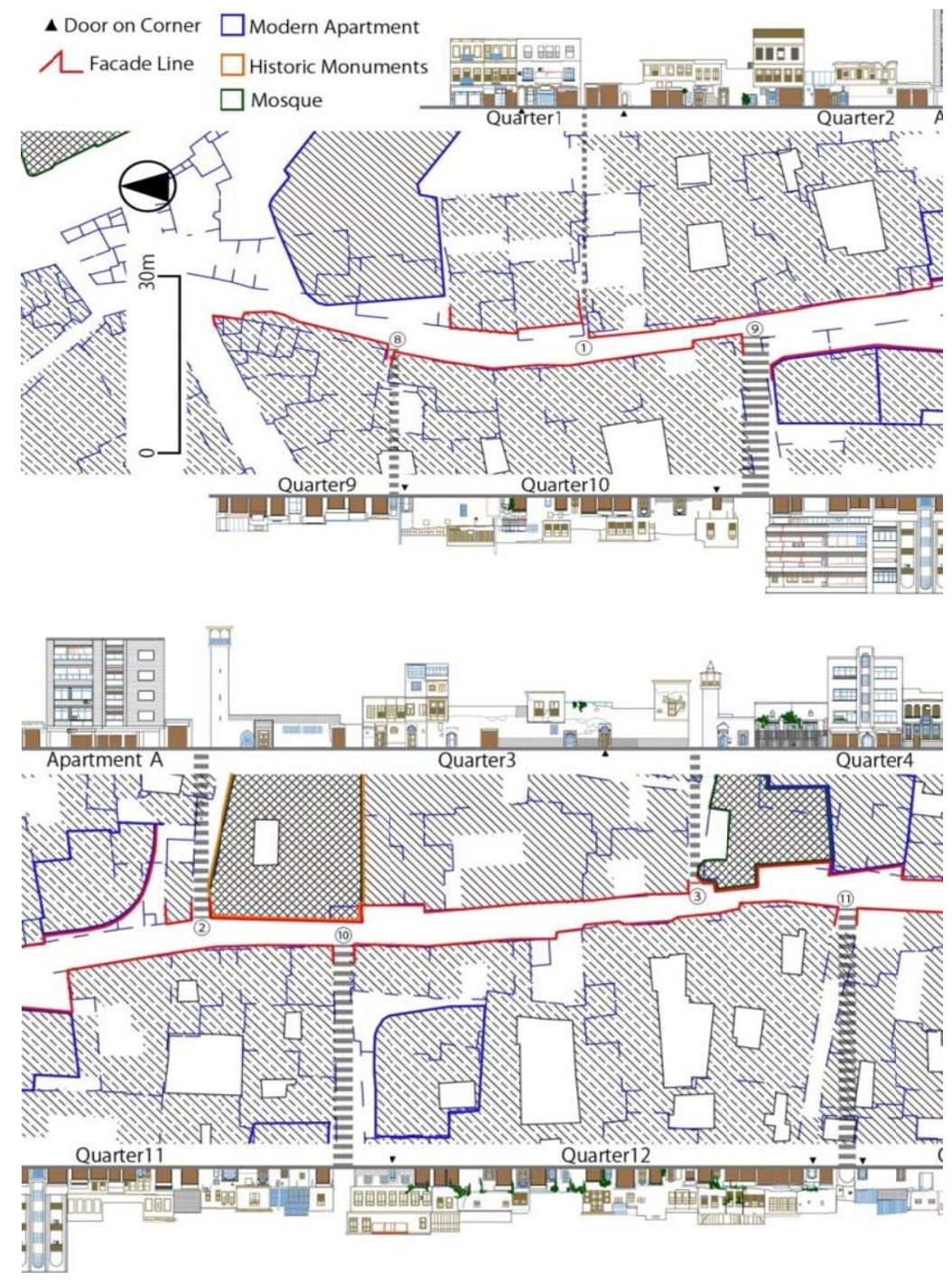

Fig. 12 Integrated facade plan (northern part).

wooden and iron windows are almost equal on the 1st floors, while there are many more wooden windows than iron windows on the 2nd floors. For this reason, it is assumed that people do not hesitate to replace wooden frames with iron frames for windows on the 1st floors (these being small and not unified) while they tend to conserve traditional style and materials on the 2nd floors. On the whole, windows, especially those on 2nd floor and above, are regarded as important original elements to be restored.

\subsubsection{Shop Shutters}

Almost all the shops have shutters on their frontage and their total surface area is the largest in the whole facade. Although the number of shutters is lower than that of Bab Srij Street, the ratio of shutters on facades on Qasr al-Hajjaj Street is 6.9\% on the east side and $9.9 \%$ on the west side. Shutters are found frequently in the south part of the street. All modern apartments have shutters on their frontage on the 1st floor. The shutters are made of zinc and their form is not traditional. Although the function of the shutters today can not be ignored, it is difficult to evaluate them as an original element.

\subsubsection{Decoration}

Traditional decoration includes Shurfa, which are wooden window covers, Hus which is bay windows that allow people to see the street while being hidden themselves and Hajar, which are traditional stone tiles 

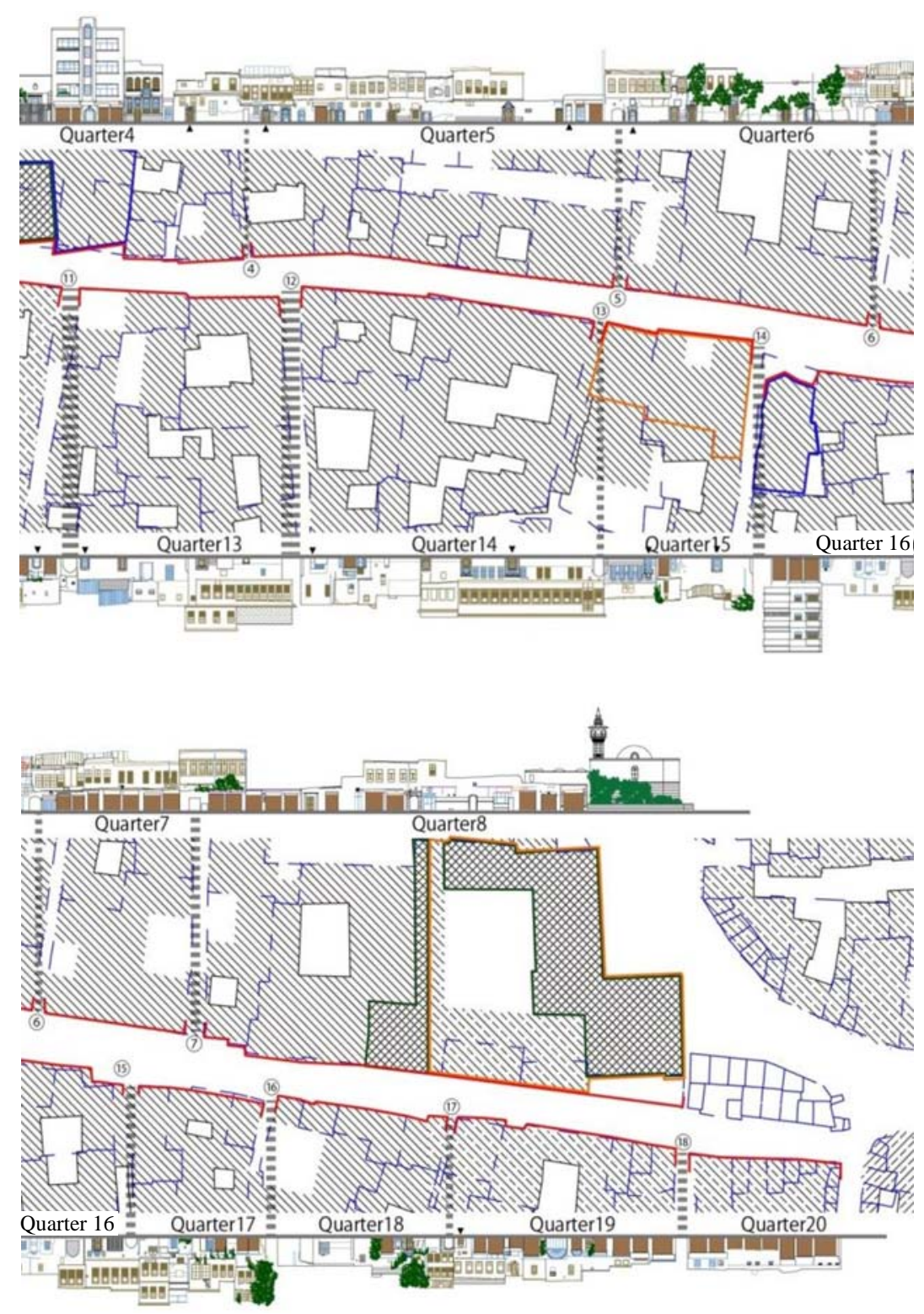

Fig. 13 Integrated facade plan (southern part).

that decorate the rims of doors. Some of these decorations have been replaced by iron materials. The bay windows of the 2nd floors and above give an impression of three-dimensionality to the landscape. The existence of revealed beams supporting bay windows and of wooden eaves also modulates the landscape. These elements are the result of extensions by the habitants and are a typical traditional townscape. Due to their delicateness and the vagueness of boundaries, it is difficult to grasp the exact number of these decorations. However, traditional decoration is certainly considered as an original element to be restored.

\section{Obstructive Elements in the Original Construction}

Shutters were not included in the original construction. Shutters were already regarded as obstacles in previous projects and they were uniformly replaced with wooden doors. However, this is not 
applicable to Qasr al-Hajjaj Street because of differences in the situation. In addition, there are some other obstructive elements such as those that were originally made from wooden materials but that were replaced by iron. It is necessary to take measurements for each obstructive element based on detailed examination.

\subsection{Shutter Obstruction}

Historically speaking, the frontage of shops was equipped with folding wooden doors. Although it is unknown when the wooden doors started to be replaced by shutters, there is photographic evidence from around 1860 showing shutters in Souk al-Taweel which are assumed to be the first shutters used in the old city (Fig. 14a). The use of shutters, which are superior to traditional wooden doors in terms of safety and ease of maintenance, rapidly spread throughout Damascus. It was accelerated by the introduction of modern apartments.

Shutters are hand-operated and rolled into boxes at the top of the frontage when the shops open. The boxes double as signs for the shops (Fig. 14b). The boxes are made of iron and there is no unity of form, colour or size. However, they have the capacity to store a rolled shutter and this makes them protrude around $1 \mathrm{~m}$ into the street. These boxes hide the arches or arch-type transoms recognized as original factors and as a result, the percentage of transoms is only $4.1 \%$ of the number of all the shop frontages in the street. Moreover, the rows of boxes, which are gaudy and not unified, also hide the revealed beams and eaves and spoil the three-dimensionality of the street landscape. These are the most serious obstructive elements in the original facades (Fig. 14c).

\subsection{Obstruction from Iron Materials and Other Devices}

Decrepitude causes materials to change. Doors and window frames that were originally made of wood tend to be replaced by iron (Fig. 14d). Makeshift repairs of collapsed walls using zinc or haphazard brick-laying is also regarded as an obstruction to the original facade. Even some traditional elements such as Shurfa and Hus have been replaced with iron or concrete materials. This change of materials must be based on demands for strength because these decorations have an aspect of practical use. However, these synthetic materials are an obstruction that do not match the wooden elements.

There are other obstructions excluded from the analysis in Section 4: the jumble of electricity cables on the walls of houses (Fig. 14e) and electricity boxes and exterior parts of air conditioners. Thick ducts on the walls of bakeries also obstruct the original facades (Fig. 14f).

In general, it has been necessary to take measures against the strong sunshine in Damascus. Today, people use zinc or even vinyl without hesitation as a material for eaves or arcade roofs. Sometimes advertisements are painted directly on to the walls.

\section{Estimation of Provisional Proposal Plan}

Based on the above research, the author will examine the provisional proposal plan created by the JICA team in this section. The suggestions in the plan seem suitable in general but their validity requires further discussion. Here examine some animation that was added to the proposal plan (Fig. 15). For example, plaster finish on some roofs and walls is much too sophisticated and spoils the original forms and structures. It also ignores small differences in height in the sequence of houses so it seems that it is not consistent as an elevation plan in some parts. Some new elements are over-designed as traditional style decorations and do not suit the original plain walls. In short, the proposal plan should be further refined and should consider the principle of respecting the original state of the buildings. In order to archive these objects, the author needs to continue with research and discussion about the history of the area, the original state of facades and the lifestyle of inhabitants. 
Compared to the integrated plan above, it is clear that the provisional proposed plan does not express the slight zigzag of the original facade. There are also some points to be noted, some modern apartments on the north side of the Naqshubandi mosque do not appear on the plan. In addition, according to the contour map created in the French mandate era, there

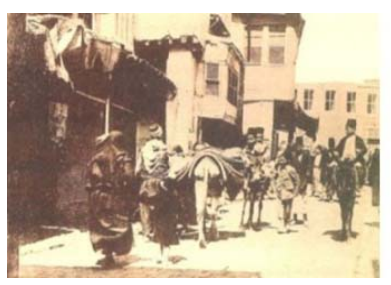

(a) SoukAl-Taweel in 1860 [12]

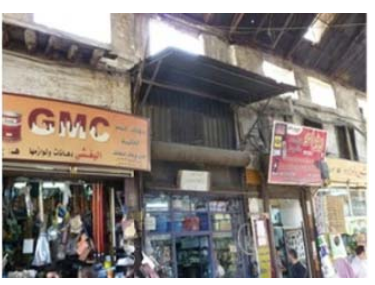

(b) Boxes as signs

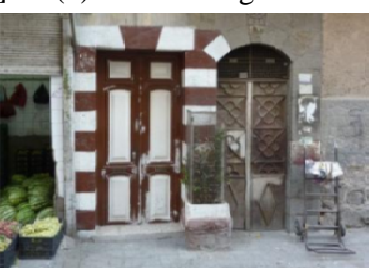

(d) Iron door (right)

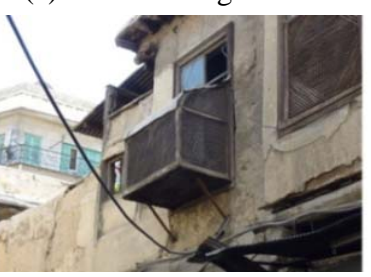

(e) Cables on Hus (f) Duct on bay window

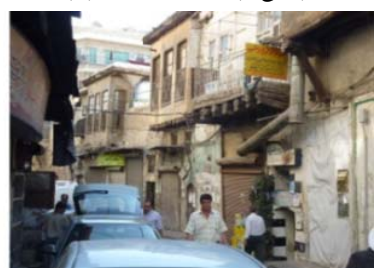

Fig. 14 Some photos about Souk al-Taweel City.
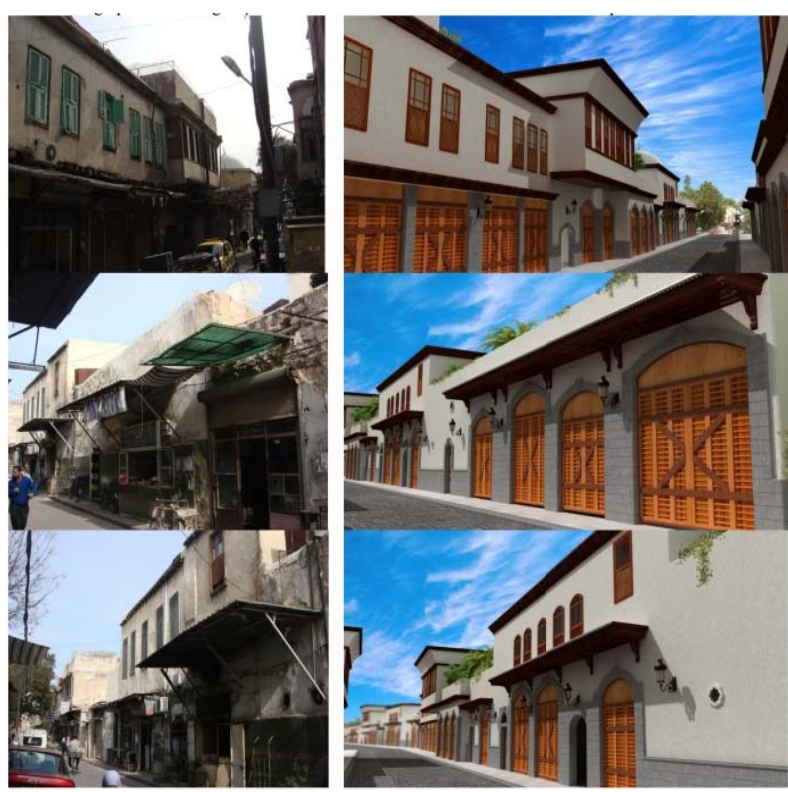

Fig. 15 Examples of proposal plans. was originally a difference in elevation of a maximum of $2 \mathrm{~m}$ or $3 \mathrm{~m}$. So these factors should also be reflected in the provisional proposal plans if necessary.

\section{Conclusions}

The restoration of the original facade of Qasr al-Hajjaj Street is composed of the following elements: doors positioned in relation to spatial composition in the floor plan, decorated windows corresponding to the raised floor and reflecting Islamic customs, bay windows as a result of extensions by habitants giving an impression of three-dimensionality to the landscape of the street, and some small decorative and structural elements such as revealed beams or eaves, Shurfa and Hus. On the other hand, there are some obstructive elements such as shop shutters, iron materials and devices related to equipment used in the shops/houses.

The issue is that these obstructive elements (shutters/iron materials) are so important from the viewpoint of daily use that they can not be easily removed. Restoring the original facade should be limited to the restoration of appearance in order to balance with the functions that are necessary today. The facade of modern apartments can also be improved using traditional style. What it is important to realize is that the principle is to provide wooden elements which have the same strength and ease of maintenance as iron elements and to prepare individual materials to suit the situation of the facade without just relying on uniform standards. It will be necessary to resolve the issues surrounding budgets and staff. Fusion of traditional craftsmanship and new techniques and materials is also important. These efforts will contribute to habitants improving their living environments by themselves.

Here is a summary of some issues to be discussed in the future. First of all, it is still possible to reproduce traditional townscape elements such as Shurfa, Hus, or Qaus, etc. as they were originally because these elements are individual parts that are 
structurally independent of the building. In short, these are freely attachable parts of the facade.

However, each of their detailed designs should be left as it was in the original in principle. So when the project is implemented, artisans should be carefully selected not only for their techniques but also their local knowledge. On the other hand, from the viewpoint of revitalizing commerce, it may be a good idea to use new materials such as glass or iron carefully. Facade cleaning is also meaningful. One of the advantages of cleaning is that detailed repairs or plaster work can be done at the same time.

It is better to incorporate modern apartments into the traditional townscape rather than to demolish them. For example, it may be efficient to put thin surface boards made of marble or gypsum on concrete walls in order to make the facade blend in with the surrounding houses.

However, there is still the question of how to deal with collapsing buildings whose structures such as pillars or beams are broken or missing. Can traditional structure be revived easily? How much will it cost? These are the issues that the author still needs to discuss.

\section{Acknowledgments}

This work was supported by JSPS KAKENHI Grant-in-Aid for Young Scientists (A) Number 24686067.

The basic ideas in this article were firstly appeared in Japanese in the Journal of the City Planning Institute of Japan [13]. Then it was presented as an article in English without peer review at the 26th Annual Congress of the Association of European Schools of Planning (AESOP 2012).

\section{References}

[1] K. Matsubara, The works of Gyoji Banshoya in the Middle East and North Africa, Journal of City Planning Institute of Japan 43 (3) (2008) 163-168.

[2] Michel Ecochard et Gyoji Banshoya, Plan Directeur de Damas, Damascus, 1968.

[3] JICA (Japan International Cooperation Agency), The Study on Urban Transportation Planning of Damascus City in the Syrian Arab Republic, Final report, 1999.

[4] JICA (Japan International Cooperation Agency), MLAE (Ministry of Local Administration and Environment), Damascus Governorate and Rural Damascus Governorate, The Study on Urban Planning for Sustainable Development Damascus Metropolitan Area in the Syrian Arab Republic, Vol. 4, Recs. International Inc. and Yachiyo Engineering Co. Ltd., 2008.

[5] JICA (Japan International Cooperation Agency), MOLA (Ministry of Local Administration), The Project for Urban Planning and Development in Damascus Metropolitan Area in the Syrian Arab Republic, Vol. 3, Project progress report, Dec. 2010.

[6] K. Matsubara, Urban conservation based on the international cooperation-A case study of the Qanawat south area, Damascus, in: The Proceedings of the International Symposium on Urban Planning, Gyeongju, 2011.

[7] R. Burns, Damascus—A History, Routledge, 2005.

[8] M. Boqvist, Architecture et développement urbain à Damas de la conquête Ottomane (922 H./1516-17) à la fondation du waqf de Murad Pasha (1017 H./1607-08), Thèse de doctorat à l’Université Paris IV, 2006.

[9] MAM (Municipal Administration Modernization) Project, Integrated Conservation and Development Plan for Damascus Old City, MAM, 2010.

[10] C. Alexander, A Pattern Language: Towns, Buildings, Construction, Oxford University Press, USA, 1977.

[11] B.S. Hakim, Arabic-Islamic Cities: Building and Planning Principles, Kegan Paul Intl, New York, 1986.

[12] N.M. Quwatly, Memoire de Damas-Photos et Commentaires 1850-1950, Dar Al-Bashaer, 2008.

[13] K. Matsubara, A study on a restoration typed facade improvement for the Qasr Al-Hajjaj Street, Journal of City Planning Institute of Japan 46 (3) (2011) 691-696. 